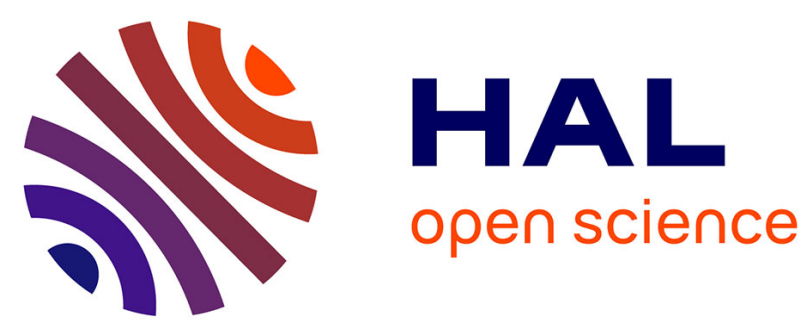

\title{
Oxygen permeation in bismuth-based materials part I: Sintering and oxygen permeation fluxes
}

\author{
Edouard Capoen, César Steil, Guy Nowogrocki, Marcin Malys, Caroline \\ Pirovano, Axel Löfberg, Elisabeth Bordes-Richard, Jean-Claude Boivin, \\ Gaetan Mairesse, Rose-Noëlle Vannier
}

\section{To cite this version:}

Edouard Capoen, César Steil, Guy Nowogrocki, Marcin Malys, Caroline Pirovano, et al.. Oxygen permeation in bismuth-based materials part I: Sintering and oxygen permeation fluxes. Solid State Ionics, 2006, 177, pp.483-488. 10.1016/j.ssi.2005.12.015 . hal-00071280

\section{HAL Id: hal-00071280 \\ https://hal.science/hal-00071280}

Submitted on 23 May 2006

HAL is a multi-disciplinary open access archive for the deposit and dissemination of scientific research documents, whether they are published or not. The documents may come from teaching and research institutions in France or abroad, or from public or private research centers.
L'archive ouverte pluridisciplinaire HAL, est destinée au dépôt et à la diffusion de documents scientifiques de niveau recherche, publiés ou non, émanant des établissements d'enseignement et de recherche français ou étrangers, des laboratoires publics ou privés. 


\section{Oxygen permeation in bismuth-based materials part I:}

\section{Sintering and oxygen permeation fluxes}

E. Capoen ${ }^{\mathrm{a}}$, M.C. Steil ${ }^{\mathrm{a}}$, G. Nowogrocki ${ }^{\mathrm{a}}$, M. Malys ${ }^{\mathrm{a}}$, C. Pirovano ${ }^{\mathrm{a}}$, A. Löfberg ${ }^{\mathrm{b}}$, E. Bordes-Richard ${ }^{\mathrm{b}}$, J.C. Boivin ${ }^{\mathrm{a}}$, G. Mairesse ${ }^{\mathrm{a}}$ and R.N. Vannier ${ }^{\mathrm{a} *}$

${ }^{a}$ Laboratoire de Cristallochimie et Physicichimie du Solide, UMR CNRS 8012, ENSCL, Université des Sciences et Technologies de Lille, B.P. 90108, 59652 Villeneuve d'Ascq Cedex, France

${ }^{b}$ Laboratoire de Catalyse de Lille, UMR CNRS 8010, USTL-ENSCL, 59655 Villeneuve d'Ascq, France

* corresponding author,

Rose-Noëlle VANNIER

LCPS-ENSCL, BP 90108, 59652 Villeneuve d'Ascq Cedex, France email : vannier@ensc-lille.fr,

Tel : 33 (0) 3204365 83,

Fax : 33 (0) 320436814 


\begin{abstract}
Oxygen permeation measurements were performed on two layered bismuth based oxide ceramics: a rhombohedral phase belonging to the $\mathrm{Bi}_{2} \mathrm{O}_{3}-\mathrm{CaO}$ system, $\left(\mathrm{Bi}_{2} \mathrm{O}_{3}\right)_{0.73^{-}}$ $(\mathrm{CaO})_{0.27}(\mathrm{BICAO})$ and a BICOVOX phase. Oxygen permeability for these systems was compared to permeability of the cubic fluorite type structure with composition $\left(\mathrm{Bi}_{2} \mathrm{O}_{3}\right)_{0.75}\left(\mathrm{Er}_{2} \mathrm{O}_{3}\right)_{0.25}(\mathrm{BE} 25)$. Low oxygen permeability was observed for the pure ceramic. As for BE25, permeability was considerably increased if $40 \mathrm{vol} \%$ of silver was added to BICAO. In contrast, permeability was not improved by addition of gold to BICOVOX. For this latter phase, the oxygen molecular exchange at the surface is clearly the limiting step in the oxygen transfer.
\end{abstract}

PACS codes : 68.35F, 66.30D, 81.05M, 84.32F

Keywords: bismuth erbium oxide, bismuth calcium oxide, BIMEVOX, oxygen permeation 


\section{Introduction}

Bismuth oxides exhibit high oxide ion conductivity. A conductivity of $1 \mathrm{~S} / \mathrm{cm}$ was observed for $\mathrm{Bi}_{2} \mathrm{O}_{3}$ itself in its $\delta$ form at $800^{\circ} \mathrm{C}$. However, these exceptional properties are limited by the melting point of the material at $830^{\circ} \mathrm{C}$, and by a dramatic phase transition at $730^{\circ} \mathrm{C}$, characterised by a large volume change which leads to mechanical strains. Several studies have been performed to stabilise this high temperature form at room temperature. By partial substitution with erbium, a $\left(\mathrm{Bi}_{2} \mathrm{O}_{3}\right)_{1-\mathrm{x}}\left(\mathrm{Er}_{2} \mathrm{O}_{3}\right)_{\mathrm{x}}$ solid solution with $0.175 \leq \mathrm{x} \leq 0.455$ was evidenced [1]. Rhombohedral phases with high conductivity at high temperature were obtained in the $\mathrm{Bi}_{2} \mathrm{O}_{3}-\mathrm{CaO}, \mathrm{Bi}_{2} \mathrm{O}_{3}-\mathrm{BaO}$ or $\mathrm{Bi}_{2} \mathrm{O}_{3}-\mathrm{SrO}$ systems [2-5]. The best properties at moderate temperatures were observed for BIMEVOX materials which derive from $\mathrm{Bi}_{4} \mathrm{~V}_{2} \mathrm{O}_{11}$ by partial substitution for vanadium with a metal [6].

Because of their conductivity at moderate temperatures, $400-700^{\circ} \mathrm{C}$, these materials could be developed as membranes for oxygen separation from air [7, 8] or as catalysts in a Catalytic Dense Membrane Reactor (CDMR) [9]. There are two concepts of oxygen separators using an oxide ion conductive membrane: current driven membranes and pressure driven membranes. In the first case, under an electrical field, molecular oxygen is dissociated at the cathode into oxide ions which migrate through the membrane and recombine as $\mathrm{O}_{2}$ at the anode. This allows the production of given amounts of oxygen under pressure. In the second case, a difference of oxygen partial pressure between an oxygen rich compartment and an oxygen poor compartment is the driving force for the migration of $\mathrm{O}_{2}$ from the rich to the oxygen poor compartment. There is no need for an external current but the membrane must be a mixed conductor to allow the reverse flow of the electrons needed for the oxygen dissociation. This mixed conductive membrane can be an intrinsically mixed conductor or a 
mixture of an oxide ion conductor and an electronic phase. The expected oxygen permeation flux in such membranes depends therefore on the difference of oxygen partial pressure between the two compartments, on the membrane thickness (the thicker the membrane, the lower will be the flux, due to diffusion limitation) and on the ionic and electronic conductivity of the membrane. Assuming the oxygen transfer is not limited by transfer of oxygen molecules at the surface, the oxygen permeation flux is given by the Wagner equation:

$$
J_{O_{2}}=\frac{R T}{(4 F)^{2}} \frac{\sigma_{a m b}}{L} \ln \frac{p O_{2}(h)}{p O_{2}(l)}
$$

where $\mathrm{pO}_{2}(\mathrm{~h})$ and $\mathrm{pO}_{2}(\mathrm{l})$ stand for the oxygen partial pressure in the higher and lower oxygen partial pressure compartment, respectively, $\mathrm{L}$ is the sample thickness, $\mathrm{T}$ is the temperature, $\mathrm{R}$ is the universal gas constant and $\mathrm{F}$ is the faraday constant. The ambipolar conductivity is defined as:

$$
\sigma_{a m b}=\frac{\sigma_{e} \sigma_{i}}{\sigma_{e}+\sigma_{i}}
$$

where $\sigma_{\mathrm{e}}$ is the electronic contribution and $\sigma_{\mathrm{i}}$ is the ionic contribution to the total conductivity.

In the case of extrinsic mixed conductors, percolation of the oxide ion conducting and the electronically conducting phases is needed. Wu and Liu found the percolation threshold to be $1 / 3$ volume fraction and the ambipolar conductivity was relatively high when the volume fraction of each phase was within the range $1 / 3$ to $2 / 3$ [10]. This was confirmed by Chen et al. who showed the oxygen permeability of a YSZ-Pd composite containing 40 vol\% Pd was 
much larger than that of a non-percolative composite containing 30 vol\% Pd [11]. When the electronic conduction is high as compared to the ionic conduction, the oxygen flux is mainly a function of the ionic conductivity.

High oxygen permeability was evidenced for perovskite materials that are intrinsic mixed conductors at high temperatures $\left(800-1100^{\circ} \mathrm{C}\right)$, and for $\mathrm{Bi}_{2} \mathrm{O}_{3}-\mathrm{Er}_{2} \mathrm{O}_{3}$ and $\mathrm{Bi}_{2} \mathrm{O}_{3}-\mathrm{Y}_{2} \mathrm{O}_{3}$ systems mixed with silver, at lower temperatures $\left(500-800^{\circ} \mathrm{C}\right)[12-15]$.

The aim of this paper is the characterisation of oxygen permeability in layered bismuth oxides. Two compositions were selected: a rhombohedral phase belonging to the $\mathrm{Bi}_{2} \mathrm{O}_{3}-\mathrm{CaO}$ system whose structure can be described as the stacking of hexagonal layers [3, 4], with $\left(\mathrm{Bi}_{2} \mathrm{O}_{3}\right)_{0.73^{-}}(\mathrm{CaO})_{0.27}$ composition (further referred to as BICAO) and a BICOVOX phase belonging to the BIMEVOX family of materials whose structure is built from $\mathrm{Bi}_{2} \mathrm{O}_{2}{ }^{2+}$ layers interspaced with oxygen deficient $\mathrm{VO}_{3.5}$ slabs. The cubic fluorite type structure with composition $\left(\mathrm{Bi}_{2} \mathrm{O}_{3}\right)_{0.75}\left(\mathrm{Er}_{2} \mathrm{O}_{3}\right)_{0.25}$ (referred to as $\mathrm{BE} 25$ ) which had been previously studied by the group of Bouwmeester et al. [12,13] was also investigated for the sake of comparison. In a first step, sintering conditions were optimised to obtain dense ceramics. In a second step, oxygen permeation fluxes were measured between $600^{\circ} \mathrm{C}$ and $700^{\circ} \mathrm{C}$ on pure ceramic membranes and 40 vol\% of metal cermet membranes. Silver was added to BE25 and BICAO. In the case of BICOVOX cermet membranes, the gold was added because silver reacts with BIMEVOX phases. The temperature of measurements was limited to $700^{\circ} \mathrm{C}$ because of the use of pyrex rings for sealing. This paper is divided into two parts. In part I, results of oxygen permeation are presented. Part II will deal with ${ }^{18} \mathrm{O} /{ }^{16} \mathrm{O}$ isotope exchange experiments which were performed to define the limiting step in the oxygen transport for these materials. 


\section{Experimental}

Dense ceramic membranes were prepared from attrition-milled powders of BE25, BICAO and BICOVOX. BE25 and BICAO powders were prepared by solid state reaction from the stoichiometric mixture of the corresponding oxides, $\mathrm{Bi}_{2} \mathrm{O}_{3}$ (Riedel de Hahn, 99.6\%, previously decarbonated at $600^{\circ} \mathrm{C}$ ), $\mathrm{Er}_{2} \mathrm{O}_{3}$ (Merck, 99\%), and calcium carbonate $\mathrm{CaCO}_{3}$, (Prolabo, > 99\%). The mixtures were heated at $600^{\circ} \mathrm{C}$ for 12 hours and then at $800^{\circ} \mathrm{C}$ for BE25 and $700^{\circ} \mathrm{C}$ for $\mathrm{BICAO}$ with intermediate grinding between each temperature. BICOVOX was prepared by co-precipitation and provided by Pharmacie Centrale de France (P.C.F.). Its actual composition was $\mathrm{Bi}_{2.02} \mathrm{Co}_{0.13} \mathrm{~V}_{0.85} \mathrm{O}_{\mathrm{z}}$. The purity of each phase was checked by means of X-ray diffraction. The as-prepared powders were too coarse to be densified. They were ball milled by attrition for 4 hours using 1-2 mm diameter zirconia balls with a $1000 \mathrm{rpm}$

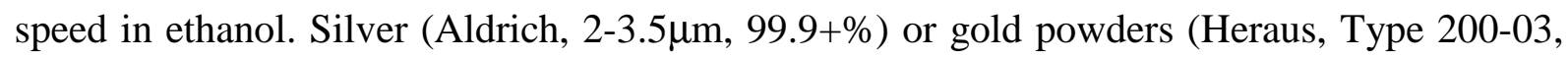
BET $0.40 \mathrm{~m} 2 / \mathrm{g},<2.5 \mu \mathrm{m})$ were used for the cermets. They were mixed with the ceramic powder in ethanol which was evaporated using a rotary evaporator. The sintering conditions were optimised using dilatometry. Green membranes, $5 \mathrm{~mm}$ diameter, 5-6 mm thick, were uniaxially pressed and then isostatically pressed under 700 bar. Dilatometric experiments (Linseis $75 / 1550$ ) were performed with a $4^{\circ} \mathrm{C} / \mathrm{min}$ heating rate, up to a maximum temperature defined as a function of the materials melting point. Cylindrical pellets for oxygen permeation, $15 \mathrm{~mm}$ diameter, about $1 \mathrm{~mm}$ thick, were prepared in the same way and sintered according to the dilatometry results. Their surfaces were mirror-polished using successive SiC papers up to 4000 grit. Their microstructures were characterised using a Jeol 5300 microscope.

Oxygen permeation measurements were performed on both pure ceramics and cermets. Measurements were also performed on BE25 and BICAO ceramics coated with silver paste 
(Aldrich, 2-3.5 $\mu \mathrm{m}, 99.9+\%$ ) on the surface. The experimental set-up described by Fouletier in [15] was used for the measurements. A schematic of this set-up is given in Fig. 1. The cylindrical membrane, $15 \mathrm{~mm}$ diameter, 1 to $2 \mathrm{~mm}$ thick, was introduced between two mullite tubes and sealed by pyrex glass rings. Experiments were carried out between $600^{\circ} \mathrm{C}$ and $700^{\circ} \mathrm{C}$. Leakage was controlled by measuring the trace oxygen content in the isolation chamber. Pure oxygen was introduced in the lower chamber and argon in the upper one. The oxygen partial pressure in the argon stream was about $2 \times 10^{-6}$ atm. The oxygen concentration in the inlet and outlet were measured by means of zirconia electrochemical oxygen gauges. The gas flows were fixed at $2.5 \mathrm{~cm}^{3} / \mathrm{sec}$. The permeation fluxes were calculated by dividing the permeation rates by the effective surface area of the disks.

Conductivity measurements as a function of oxygen partial pressure were carried out in the $500-600^{\circ} \mathrm{C}$ range on $\mathrm{BE} 25$ and $\mathrm{BICAO}$ pure ceramics. The pellets were $8 \mathrm{~mm}$ diameter and $3 \mathrm{~mm}$ thick. A zirconia oxygen pump was used to introduce a given amount of oxygen which was controlled by means of a zirconia electrochemical oxygen gauge. Impedance measurements were performed with Solartron 1260 impedance analyser with a $50 \mathrm{mV}$ amplitude signal over the $1 \mathrm{~Hz}$ to $1 \mathrm{MHz}$ frequency range. A gold paste (6440 $\mathrm{DMC}^{2}$ France) was used as the electrode material. It was deposited by painting and treated at $650^{\circ} \mathrm{C}$ for 1 hour with a $5^{\circ} \mathrm{C} / \mathrm{min}$ heating-cooling rate.

\section{Results and discussion}

a) Sintering conditions

To prepare dense ceramics, the sintering conditions of each ceramic were optimised. Dilatometry was performed on both pure ceramics and cermets. The corresponding shrinkage 
curves are given in Fig.2. In general, cermets with silver exhibit a lower melting point than pure ceramics. The rate of shrinkage and temperature of maximum shrinking rate, and the temperature above which grain growth is expected, are reported in table 1 . While close critical temperatures were found for BICAO and BICOVOX, a higher critical temperature was observed for BE25 which exhibits a higher melting point. The addition of silver led to a higher sintering rate. After several attempts, BE25 membranes were sintered for 1 hour at $900^{\circ} \mathrm{C}, \mathrm{BICAO}$ for 2 hours at $720^{\circ} \mathrm{C}$ and BICOVOX for $1 \mathrm{~h}$ at $750^{\circ} \mathrm{C}$ with a $4^{\circ} \mathrm{C} \cdot \mathrm{min}^{-1}$ heating and cooling rate. Membranes with a relative density higher than $95 \%$ were obtained in all cases.

Secondary electron and back scattering electron micrographs of BICOVOX pure ceramic and BICOVOX-Au and BE25-Ag cermets are reported in Fig. 3. For BE25-Ag cermet, the ceramic appears as white and silver as black on the micrographs, in contrast to BICOVOX-Au for which ceramic is black and gold is light grey. These micrographs revealed dense membranes with grain sizes of $5 \mu \mathrm{m}$ for pure BICOVOX and smaller grains in the case of the cermets. An homogeneous distribution of the ceramic and metal was generally observed.

b) Conductivity of pure ceramic

In their study of oxygen permeability at various oxygen partial pressures, Boukamp et al. [12] evidenced a p-type electronic conductivity for BE25 and evaluated the electronic transference number to be less than $1 \%$ at $650^{\circ} \mathrm{C}$. Guillodo et al. [17] evidenced a low p-type conductivity for BICOVOX at temperatures higher than $550^{\circ} \mathrm{C}$. An electronic transport number of $3 \%$ was calculated at $650^{\circ} \mathrm{C}$. Conductivity was measured by impedance spectroscopy for the three pure ceramics. Arrhenius plots are given in Fig. 4. BE25 and 
BICOVOX exhibit similar conductivity values at temperatures higher than $600^{\circ} \mathrm{C}$ and therefore a similar rate of oxygen permeability should be expected for these two compositions. BICAO conductivity at $600^{\circ} \mathrm{C}$ is one order of magnitude lower than BICAO and BE25. It exhibits a phase transition at $730^{\circ} \mathrm{C}$. The high temperature form $\left(\beta_{1}\right)$ is a pure oxide ion conductor whereas a p-type semi-conduction was evidenced in the low temperature domain $\left(\beta_{2}\right)$ [4]. This was confirmed by the evolution of the conductivity as a function of the oxygen partial pressure (Fig. 5). Measurements were performed at 500, 550 and $600^{\circ} \mathrm{C}$. In the whole domain of temperature, an increase of the conductivity was observed when the oxygen partial pressure increased, indicating a p-type semi-conduction. At $600^{\circ} \mathrm{C}$, the electronic conduction under air was at least $15 \%$ of the total conduction.

c) Oxygen permeation fluxes

Oxygen permeation fluxes were measured between $600^{\circ} \mathrm{C}$ and $700^{\circ} \mathrm{C}$. Values at selected temperatures are given in table 2 together with membrane thickness and corresponding oxygen partial pressures. Their evolution versus temperature is reported in Fig. 6. Oxygen permeation fluxes obtained on BE25 and BE25-Ag membranes are in good agreement with values reported by Bouwmeester [12, 13]. Although the conductivity of BICAO was lower, similar oxygen permeation fluxes were observed for BE25 and BICAO pure ceramics. Similar fluxes were measured on membranes silver coated on the surface but fluxes were increased by at least one order of magnitude when 40 vol \% of silver was added. In contrast, very low oxygen permeation fluxes were obtained for BICOVOX, which could not be increased by addition of gold. 
It is notable that oxygen permeation fluxes measured for the BICAO-Ag cermet are of the same order of magnitude than those reported by Lee and $\mathrm{Wu}$ for $\mathrm{BiBaO}-\mathrm{Ag}[18]$ and BiSrO-Ag [19] for $\beta_{2}$ rhombohedral forms. These authors showed that the oxygen permeation fluxes were increased by one order of magnitude in the $\beta_{1}$ domain, so that higher fluxes should be expected for BICAO in the $\beta_{1}$ domain. Unfortunately, our experimental set-up being limited to $700^{\circ} \mathrm{C}$, we were not able to measure the oxygen permeation for BICAO in its $\beta_{1}$ form which is stable only above $730^{\circ} \mathrm{C}$. The higher semi-conduction of BICAO as compared to BE25 explains oxygen permeation fluxes in the same order of magnitude for these two compositions although BICAO is less conductive in this domain of temperature. Silver addition to BE25 led to a higher increase of oxygen permeation compared to BICAO cermet, in agreement with the higher ionic conductivity of BE25. Two parameters govern the oxygen transport in such membranes: i) the bulk diffusion controlled by the ambipolar conductivity (oxide ion conduction and electron hole conduction) and ii) the rate of exchange of $\mathrm{O}_{2}$ molecules at the surface of the membrane. Ten Elshof et al [20] characterised the oxygen permeation properties of dense BE25-Ag cermet membranes with different silver contents. Under the percolation threshold, they evidenced an increase of oxygen flux when silver content increased and attributed this to faster kinetics of surface oxygen exchange in the presence of silver. In the present study, similar oxygen fluxes were measured on pure ceramic membranes and membranes with a silver layer painted on the surface. In contrast, as observed by ten Elshof on BE25-Ag, oxygen permeation was considerably increased by addition of 40 vol\% silver in the bulk. This indicates that, in the case of BE25 and BICAO pure ceramics, the electronic conduction is limiting the oxygen transfer whereas for cermets, above the permeation threshold, the electronic conduction is no longer limiting. However, for the BICAO-Ag cermet at $600^{\circ} \mathrm{C}$ and assuming bulk diffusion as the limiting step in the oxygen transfer, a theoretical permeation flux of $4 \cdot 10^{-8} \mathrm{~mol} . \mathrm{cm}^{-2} \cdot \mathrm{s}^{-1}$ would be expected by considering 
the conductivity of pure BICAO $\left(\sigma_{\mathrm{i}}=8.10^{-3} \mathrm{~S} . \mathrm{cm}^{-1}\right.$ at $\left.600^{\circ} \mathrm{C}\right)$ and taking into account the volume fraction of silver. A lower flux of $9.92 .10^{-9} \mathrm{~mol} . \mathrm{cm}^{-2} \cdot \mathrm{s}^{-1}$ was measured. The same feature was observed for BIBAO-Ag cermet by Lee [18], who suggested that the flux was at least partly limited by the surface reaction rate. One technique allowing the characterisation of the kinetics of transfer is the ${ }^{18} \mathrm{O} /{ }^{16} \mathrm{O}$ Isotope Exchange Depth Profile Technique based on Secondary Ion Mass Spectrometry. This technique was applied to BE25 and BICAO ceramics and cermets. It confirmed slow kinetics of oxygen transfer at the surface of pure ceramics. The rate of oxygen surface exchange is increased by a factor of almost 100 for cermets. The results will be described in part II.

In the case of BICOVOX, oxygen permeation was not improved by addition of gold. The ${ }^{18} \mathrm{O} /{ }^{16} \mathrm{O}$ Isotope Depth Profile Technique based on Secondary Ion Mass Spectrometry was performed on BIMEVOX membranes and confirmed that the kinetics of exchange at the surface of these materials are very slow [21].

\section{Conclusion}

Oxygen permeation measurements were performed on two layered bismuth-based oxides: a rhombohedral phase belonging to the $\mathrm{Bi}_{2} \mathrm{O}_{3}-\mathrm{CaO}$ system, $\left(\mathrm{Bi}_{2} \mathrm{O}_{3}\right)_{0.73}-(\mathrm{CaO})_{0.27}$ (BICAO) of $\beta_{2}$ type, which is a p-type semiconductor and a BICOVOX phase, which exhibits a small p-type semi-conductivity. Oxygen permeation fluxes were compared to those obtained on the cubic fluorite type structure with composition $\left(\mathrm{Bi}_{2} \mathrm{O}_{3}\right)_{0.75}\left(\mathrm{Er}_{2} \mathrm{O}_{3}\right)_{0.25}$ (BE25). Low oxygen permeability was observed for the pure ceramic. It was considerably increased when 40 vol\% of silver was added to BE25 or BICAO. In contrast, the permeability was not improved by addition of gold to BICOVOX. In this case, the oxygen molecular exchange at 
the surface is clearly the limiting step in the oxygen transfer. The kinetics are not improved by addition of gold which confirms the poor activity of this metal for oxygen dissociation. The characterisation of oxygen transfer in BICAO and BE25 by the ${ }^{18} \mathrm{O} /{ }^{16} \mathrm{O}$ Isotope Exchange Depth Profile Technique will be described in part II. Thanks to their high conductivity, bismuth based oxides allow oxygen permeation at moderate temperature which makes them promising catalytic materials in Catalytic Dense Membrane Reactors for selective oxidation [9].

\section{Acknowledgements}

This study was performed within the framework of a "Contrat de Programme de Recherche" (CPR) between L'Air Liquide and the CNRS within the CNRS "Programme Matériaux" framework. Both L'Air Liquide and the CNRS are acknowledged for their financial support.

\section{References}

1. M.J. Verkerk, K. Keizer, A.J. Burggraaf, J. Appl. Electrochem. 10 (1980), p. 81.

2. P. Conflant, J.C. Boivin, D. Thomas, J. Solid State Chem. 18 (1976), p. 133.

3. P. Conflant, J.C. Boivin, D. Thomas, J. Solid State Chem. 35 (1980), p. 192.

4. P. Conflant, Thesis (University of Lille, 1985).

5. J.C. Boivin, D. Thomas, Solid State Ionics 5 (1981), p. 523.

6. F. Abraham, J.C. Boivin, G. Mairesse, G. Nowogrocki, Solid State Ionics 40/41 (1990), p.934. 
7. J.C. Boivin, C. Pirovano, G. Nowogrocki, G. Mairesse, P. Labrune, G. Lagrange, Solid State Ionics 113-115 (1998), p. 639.

8. G. Mairesse, C.R. Acad. Sci. Paris, t.2, serie II c (1999), p. 651.

9. A. Löfberg, S. Boujmiai, E. Capoen, M.C. Steil, C. Pirovano, R.N. Vannier, G. Mairesse, E. Bordes-Richard, Catalysis Today $91-92$ (2004), p. 79.

10. Z.Wu, M. Liu, Solid State Ionics 93 (1997), p. 65.

11. C.S. Chen, B.A. Boukamp, H.J.M. Bouwmeester, G.Z. Cao, H. Kruidhof, A.J.A. Winnubst, A.J. Burggraaf, Solid State Ionics 76 (1995), p. 23.

12. H.J.M. Bouwmeester, H. Kruidhof, A.J. Burggraaf, P.J. Gellings, Solid State Ionics 53-56 (1992), p. 460.

13. H.J.M Bouwmeester, A.J. Burggraaf, The CRC Handbook of Solid State Electrochemistry, P.J. Gellings, H.J.M. Bouwmeester eds, CRS Press (1997), p. 481.

14. Y. Shen, M. Liu, D. Taylor, S. Bolagopal, A. Joshi, K. Krist, Proceedings of the $2^{\text {nd }}$ Int. Symposium on Ionic and Mixed Conducting Ceramics, The Electrochemical Society, Vol 9412 (1994), p. 574.

15. M. Liu, A.V. Joshi, Y. Shen, K. Krist, US Patent 5,273,628 (1993)

16. J. Fouletier, P. Fabry, M. Kleitz, J. Electrochem. Soc. 123(2) (1976), p. 204.

17. M. Guillodo, J. Fouletier, L. Dessemond, P. Del Gallo, J. Eur. Ceram. Soc. 21 (2001), p. 2331 .

18. T.H. Lee, Y.L. Yang, A.J. Jacobson, Solid State Ionics 134 (2000), p. 331.

19. K. Wu, S. Xie, G.S. Jiang, W. Liu, C.S. Chen, Journal of Membrane science 188 (2001), p.189.

20. J.E. ten Elshof, N.Q. Nguyen, M.W. den Otter, H.J.M. Bouwmeester, J. Electrochem. Soc. Vol 144, N 12, (1997), 4361. 
21. R.N. Vannier, S.J. Skinner, R.J. Chater, J.A. Kilner, G. Mairesse, Solid State Ionics 160 (2003), p. 85. 
Figure captions

Fig. 1. Scheme of the experimental set-up for permeation measurement.

Fig. 2. Shrinkage curves of (a) BE25 and BE25-Ag (40 vol\%) (b) BICAO and BICAO-Ag (40 vol\%) (c) BICOVOX and BICOVOX-Ag (40 vol\%).

Fig. 3. Secondary electron (left) and back scattering electron (right) micrographs of (a) BICOVOX pure ceramic, (b) BICOVOX-Au (40 vol\%) cermet, (c) BE25-Ag (40 vol\%) cermet.

Fig. 4. Conductivity of BICAO as a function of the oxygen partial pressure.

Fig. 5. Arrhenius plot of the conductivity for BE25, BICAO and BICOVOX compared to YSZ.

Fig. 6. Oxygen permeation fluxes in function of the temperature through BE25, BE25-Ag (40 vol\%), BICAO, BICAO-Ag (40 vol\%), BICOVOX and BICOVOX-Au (40 vol\%) ceramic membranes. 
Table 2: Rate of shrinkage, temperature of maximum shrinking rate and temperature above which grain growth is expected for BE25, BE25-Ag, BICAO, BICAO-Ag, BICOVOX, BICOVOX-Au ceramics

\begin{tabular}{|l|c|c|c|}
\hline & $\begin{array}{c}\text { Rate of shrinkage } \\
\left(\mu \mathrm{m} /{ }^{\circ} \mathrm{C}\right)\end{array}$ & $\begin{array}{c}\text { Temperature of maximum } \\
\text { shrinking rate }\left({ }^{\circ} \mathrm{C}\right)\end{array}$ & $\begin{array}{c}\text { Temperature of grain } \\
\text { growth starting }\left({ }^{\circ} \mathrm{C}\right)\end{array}$ \\
\hline BE25 & 5.5 & 771 & 950 \\
\hline BE25-Ag & 3.6 & 730 & 900 \\
\hline BICAO & 7.8 & 708 & 800 \\
\hline BICAO-Ag & 5.0 & 655 & 800 \\
\hline BICOVOX & 6.7 & 630 & 800 \\
\hline BICOVOX-Au & 6.7 & 636 & 800 \\
\hline
\end{tabular}

Table 1: Thickness, oxygen partial pressures and oxygen permeation fluxes measured at several temperatures for BE25, BE25-Ag, BICAO, BICAO-Ag, BICOVOX, BICOVOX-Au

\begin{tabular}{|l|c|c|c|c|c|}
\hline & $\begin{array}{c}\text { thickness } \\
(\mathrm{cm})\end{array}$ & $\begin{array}{c}\mathrm{T} \\
\left({ }^{\circ} \mathrm{C}\right)\end{array}$ & $\begin{array}{c}\text { low } \mathrm{PO}_{2} \\
(\mathrm{~atm})\end{array}$ & $\begin{array}{c}\text { high } \mathrm{PO}_{2} \\
(\mathrm{~atm})\end{array}$ & $\begin{array}{c}\mathrm{JO}_{2} \\
\left(\mu \mathrm{mole} . \mathrm{cm}^{-2} \mathrm{~s}^{-1}\right.\end{array}$ \\
\hline BE25 & 0.112 & 600 & 1 & $1.4 .10^{-6}$ & $0.71 .10^{-3}$ \\
& & 650 & 1 & $1.4 .10^{-6}$ & $1.93 .10^{-3}$ \\
& & 700 & 1 & $1.4 .10^{-6}$ & $5.11 .10^{-3}$ \\
\hline BE25-Ag & 0.129 & 650 & 1 & $2.0 .10^{-6}$ & $97.4 .10^{-3}$ \\
& & 680 & 1 & $2.0 .10^{-6}$ & $179.10^{-3}$ \\
\hline BICAO & 0.120 & 600 & 1 & $2.2 .10^{-6}$ & $1.23 .10^{-3}$ \\
& & 650 & 1 & $2.2 .10^{-6}$ & $2.29 .10^{-3}$ \\
\hline BICAO-Ag & 0.075 & 600 & 1 & $2.5 .10^{-6}$ & $9.92 .10^{-3}$ \\
& & 680 & 1 & $2.5 .10^{-6}$ & $29.5 .10^{-3}$ \\
\hline BICOVOX & 0.171 & 650 & 1 & $1.9 .10^{-6}$ & $1.6 .10^{-4}$ \\
\hline BICOVOX-Au & 0.114 & 610 & 1 & $2.0 .10^{-6}$ & $0.4 .10^{-4}$ \\
& & 650 & 1 & $2.0 .10^{-6}$ & $1.6 .10^{-4}$ \\
& & 690 & 1 & $2.0 .10^{-6}$ & $4.6 .10^{-4}$ \\
\hline
\end{tabular}




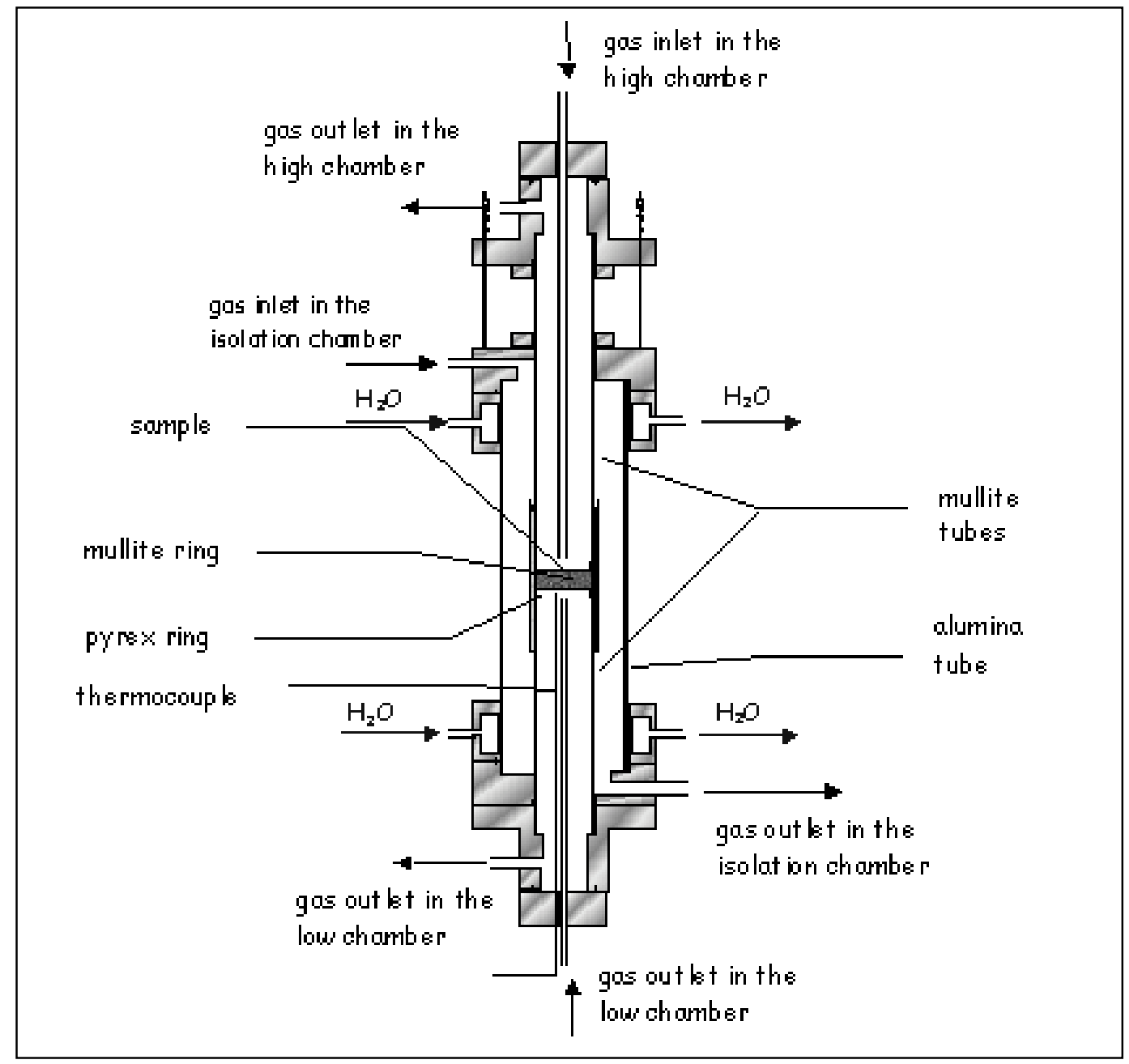

Fig. 1. Scheme of the experimental set-up for permeation measurement. 

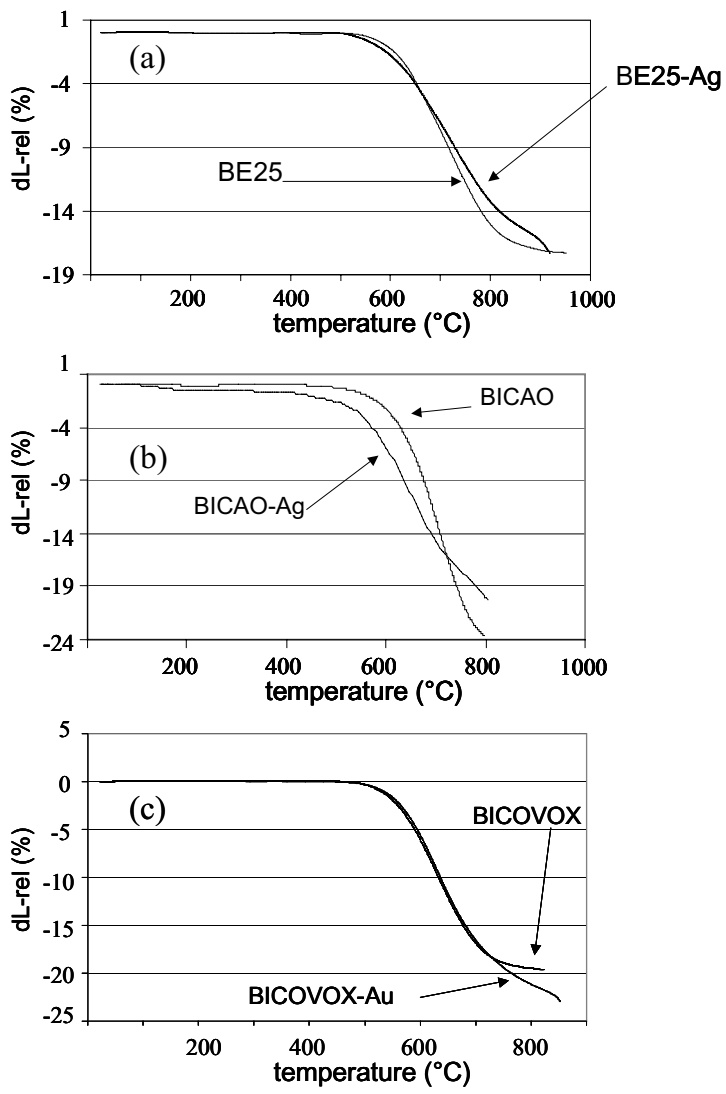

Fig. 2. Shrinkage curves of (a) BE25 and BE25-Ag (40 vol\%) (b) BICAO and BICAO-Ag (40 vol\%) (c) BICOVOX and BICOVOX-Ag (40 vol\%). 


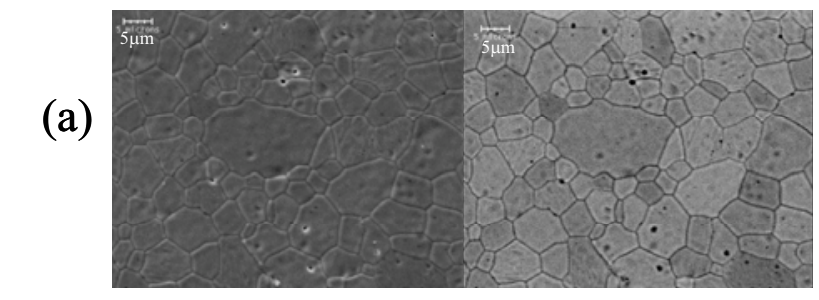

(b)

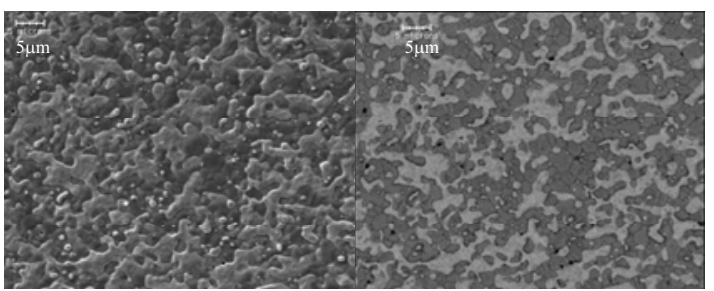

(c)

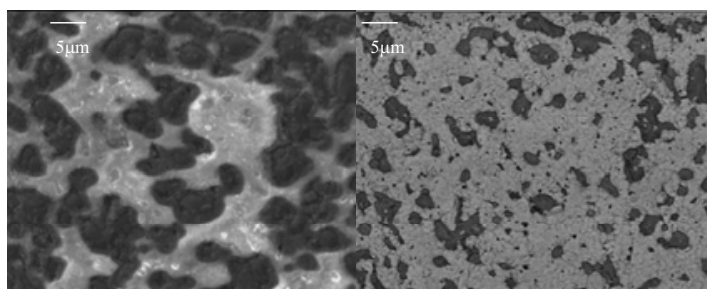

Fig. 3. Secondary electron (left) and back scattering electron (right) micrographs of (a) BICOVOX pure ceramic, (b) BICOVOX-Au (40 vol\%) cermet, (c) BE25-Ag (40 vol\%) cermet. 


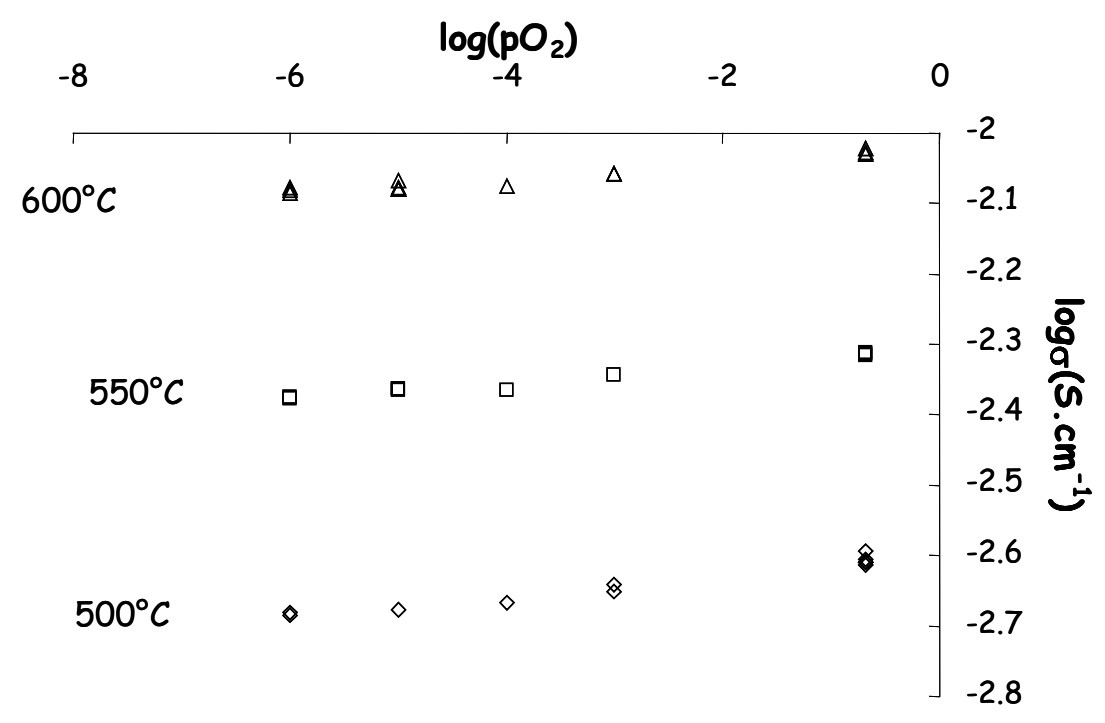

Fig. 4. Conductivity of BICAO in function of the oxygen partial pressure. 


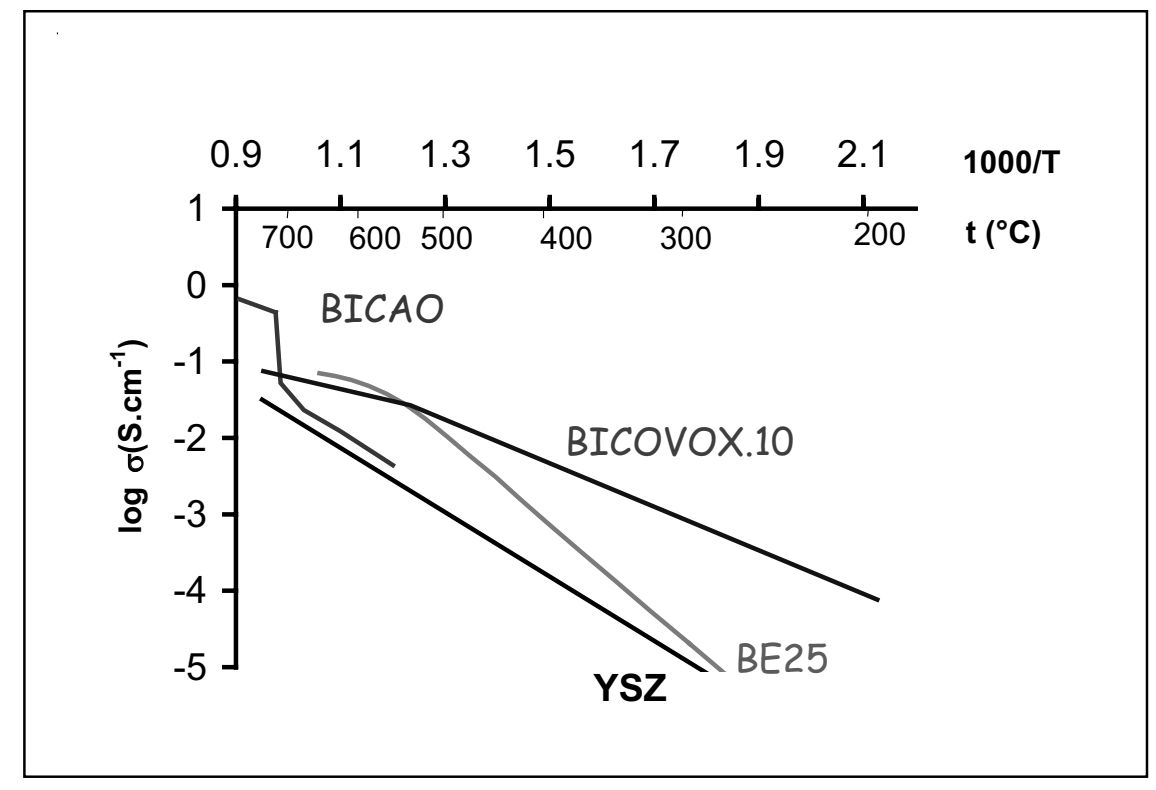

Fig. 5. Arrhenius plot of the conductivity for BE25, BICAO and BICOVOX compared to YSZ. 


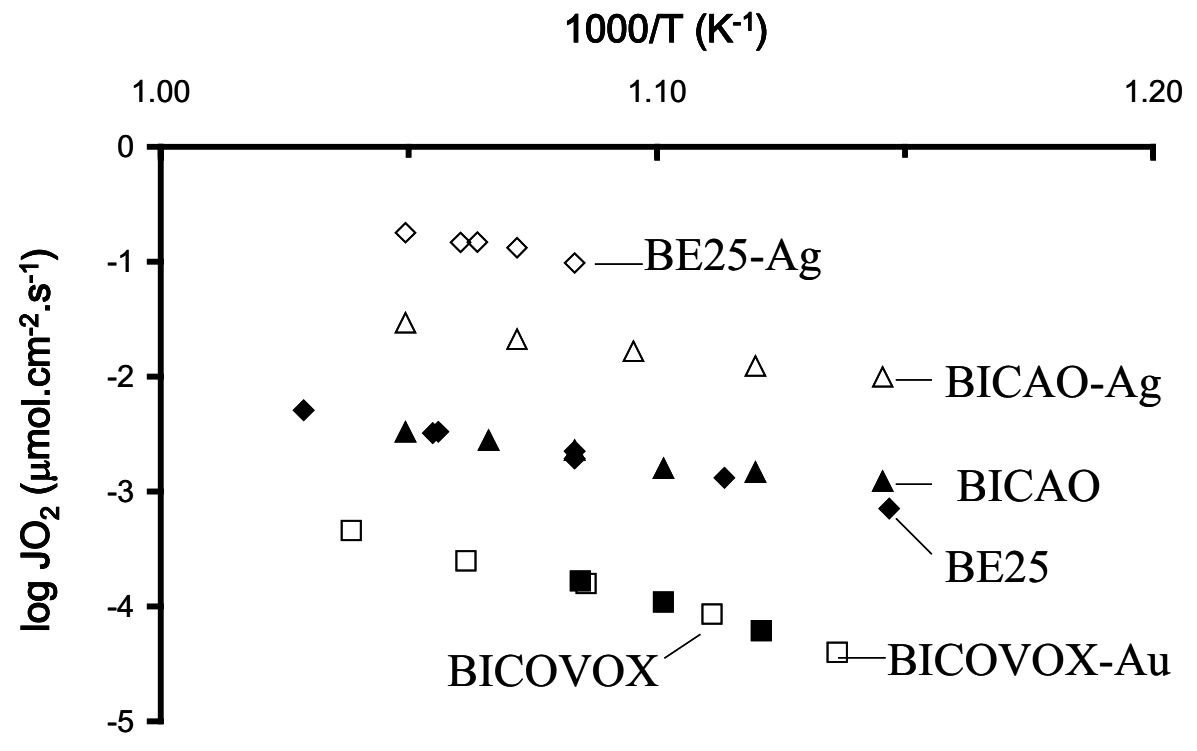

Fig. 6. Oxygen permeation fluxes in function of the temperature through BE25, BE25-Ag (40 vol\%), BICAO, BICAO-Ag (40 vol\%), BICOVOX and BICOVOX-Au (40 vol\%) ceramic membranes. 